УДК 343.985

\title{
В.В. Цыбульский
}

\section{МЕТОДОЛОГИЧЕСКИЕ ОСНОВЫ РАССЛЕДОВАНИЯ КОРРУПЦИОННЫХ ПРЕСТУПЛЕНИЙ, СОВЕРШЁННЫХ СОТРУДНИКАМИ ГИБДД}

Коррупционные преступления, совершаемые сотрудниками ГИБДД, имеют особенности, которыми они отличаются от других коррупционных преступлений. Эти особенности имеют значение для решения вопроса эффективного выявления и расследования преступлений этого вида. При этом особое внимание при расследовании следует обращать на использование сотрудниками ГИБДД предоставленных им законом должностных полномочий, а также на то, какие субъективные права предоставляются в результате злоупотребления ими этими полномочиями. Примечательно то, что должностные полномочия выступают в ходе совершения коррупционных преступлений сотрудниками ГИБДД в качестве средства преступления, а также, в отдельных случаях, в качестве стимула, подталкивающего к совершению конкретного преступления данного вида. В связи с этим уже на начальном этапе расследования следователь должен быть готов к оказанию противодействия со стороны виновных в преступлении лиц установлению всех обстоятельств совершённого преступления. В соответствии с этими особенностями в частную методику расследования коррупционных преступлений, совершённых сотрудниками ГИБДД, должны быть включены рекомендации, в которых принимается во внимание специфика совершения названных коррупционных преступлений.

Ключевые слова: коррупционные преступления, сотрудники ГИБДД, методологические основы расследования, частная методика расследования, должностные полномочия.

DOI: $10.35634 / 2412-9593-2021-31-4-711-716$

Коррупция разнообразна в своих проявлениях, но во всех случаях она представляет угрозу существующему порядку управления в государстве ${ }^{1}$. Она всегда ставит под удар авторитет государственной власти, поскольку публичный интерес заменяет личным интересом конкретного лица, которое стремится получить выгоду, не считаясь с требованиями закона. Коррупция - это негативное социальное явление, которое способно привести к параличу власти, к блокированию важных для населения социально-политических программ. О коррупции можно даже сказать, что это приватизация публичной власти в интересах лиц, занимающих определённое должностное положение в государственном аппарате 2 . Проявления коррупции всегда имеют негативные последствия для государства, поскольку ею ставится под сомнение его способность контролировать соответствующую социальнополитическую ситуацию. Коррупция в глазах населения - это всегда проявление бессилия государства в решении определённых социальных проблем ${ }^{3}$. Поэтому одной из основных задач государства является борьба с коррупцией во всех её проявлениях. Последовательность и бескомпромиссность этой борьбы вызывает уважение у граждан, которые видят непреклонную волю государства и его готовность разрешать имеющиеся проблемы.

Наиболее опасными из коррупционных проявлений являются коррупционные преступления. Они причиняют наибольший вред авторитету государственной власти ${ }^{4}$, ставят под угрозу управляемость государственными органами при решении соответствующих задач. По этой причине государство должно уделять особое внимание такому коррупционному проявлению, как коррупционные преступления. В силу их повышенной опасности должны приниматься самые эффективные меры и средства пресечения данного вида преступных посягательств, то есть вполне очевидно, что борьба с коррупционными преступлениями должна быть одним из направлений уголовной политики государства.

\footnotetext{
${ }^{1}$ Подольная Н.Н. Криминалистическая характеристика должностных коррупционных преступлений // Российский хороший журнал. Юридические науки. 2020. № 1 (3). С. 6-27.

${ }^{2}$ Подольный Н.А., Подольная Н.Н. Системная коррупция - системная угроза взаимодействию между обществом и государством // Криминологический журнал Байкальского государственного университета экономики и права. 2014. № 3. С. 33-39.

${ }^{3}$ Подольный Н.А. Системная коррупция: проблемы определения и борьбы с ней // Проблемы права. 2016. № 1 (55). C. 125-130.

${ }^{4}$ Подольный Н.А. Противодействие коррупции в Российской Федерации: тенденции и перспективы // Наука. Общество. Государство. 2019. Т. 7, № 4 (28). С. 79-83.
} 
С этой целью необходимо уделять внимание упреждению совершения данных преступлений, их выявлению и расследованию. Кроме того, умело проводимая деятельность в этом направлении позволит сохранить доверие населения к государственной власти, предотвратит отчуждение людей от институтов государства.

Однако, чтобы бороться с коррупционными преступлениями, нужно иметь чёткое представление о том, что под ними понимается. Законодательство, в том числе уголовное, не содержит определения коррупционных преступлений. Более того, в уголовном законодательстве не используется и термин «коррупционные преступления». Это, безусловно, создает определенные трудности в толковании данного понятия, нежелательные для практики борьбы с этим видом преступности. Объяснить отсутствие такого определения в законодательстве можно тем, что ещё нет достаточного теоретического осмысления, а в юридической науке пока не сформировалось однозначного понимания этого вида общественно опасных деяний. Хотя практика, на наш взгляд, уже накопила достаточный объём материала для того, чтобы можно было его обобщить, проанализировать и сделать вывод о том, что следует понимать под данным видом преступлений и как следует квалифицировать данные деяния. На сегодняшний день можно смело утверждать, что существующая многозначность в определении коррупционных преступлений вполне преодолима. Это значит, что пришло время и для законодательных инициатив, благодаря которым можно было бы получить законодательно закреплённое определение коррупционных преступлений.

Определение того, что понимается под коррупционным преступлением, необходимо не только для деятельности по квалификации преступлений, но и для деятельности по их расследованию. Это понятие нужно для формирования соответствующих частных методик расследования названных преступлений. Оно должно давать представление о том, что необходимо расследовать, в частности, благодаря ему должно быть сформировано представление об обстоятельствах, способе совершения соответствующих преступлений. Это позволит определить те тактические задачи, которые должны решаться уже на начальном этапе предварительного расследования. Следователь, опираясь на это знание, сможет на начальном этапе расследования определить те способы и средства, которые должны использоваться для установления обстоятельств совершённого деяния. В этом состоит прикладное значение определение понятия «коррупционное преступление», оно позволит увидеть признаки преступлений, которые обозначаются этим понятием для того, чтобы использовать их для оптимизации проводимого расследования.

Вполне очевидно и то, что при определении коррупционных преступлений необходимо исходить из уже имеющихся и закреплённых в действующем законодательстве понятий: - «коррупция» и «преступление». То, что следует понимать под коррупцией определено в ст. 1 Федерального закона от 25.12.2008 № 273-Ф3 «О противодействии коррупции» ${ }^{5}$ Основными признаками коррупции здесь названы: использование физическим лицом своего должностного положения вопреки интересам общества и государства; преследование цели получения выгоды в виде денег, ценностей, иного имущества или услуг имущественного характера, а также получения имущественных прав для себя или третьих лиц. Также здесь перечислены формы проявления коррупции (дача, получения взятки и т. п.). Такое определение даёт исчерпывающее представление о коррупции не только, как о социальном явлении, но и как о вполне конкретных действиях. Из него понятно, что коррупция может проявляться в деяниях, имеющих различную степень общественной опасности. Это могут быть административные правонарушения и иные виды правонарушений. Из перечисленных в названной норме закона проявлений коррупции очевидно то, что законодателя в большей мере тревожили проявления, представляющие наибольшую общественную опасность - коррупционные преступления. Именно к таковым относятся дача и получение взятки, злоупотребления полномочиями, коммерческий подкуп.

Другой критерий, позволяющий определить, что следует понимать под коррупционным преступлением определён в ст. 14 УК РФ $\Phi^{6}$. Здесь названы признаки преступления, в частности, что для преступных проявлений коррупции характерна соответствующая общественная опасность, виновность соответствующего деяния, его уголовная наказуемость и запрещённость действующим уголовным законодательством. При этом законодатель в ст. 1 Федерального закона от 25.12.2008 № 273-Ф3

\footnotetext{
${ }^{5}$ Федеральный закон от 25.12.2008 № 273-Ф3 «О противодействии коррупции»// Российская газета. 2008. 30 дек.

${ }^{6}$ Уголовный кодекс Российской Федерации: Федеральный закон от 13.06.1996 № 63-Ф3 [принят Государственной Думой 24 мая 1996, одобрен Советом Федерации 5 июня 1996 г.] // Собрание законодательства Российской Федерации. 1996. № 25. Ст. 2954.
} 
Методологические основы расследования коррупционных преступлений...

713

ЭКОНОМИКА И ПРАВО

2021. Т. 31, вып. 4

«О противодействии коррупции» достаточно однозначно указал на то, что именно коррупционные преступления представляют наибольшую опасность, и общество, государство нуждаются первоочередной защите от них. Причём перечислением соответствующих деяний законодатель указал, какие именно коррупционные преступления представляют повышенную опасность. Это следующие преступления: дача и получение взятки, злоупотребления полномочиями, коммерческий подкуп. Здесь вполне уместно согласиться с законодателем в части того, названные преступления характеризуются повышенной опасностью для государства и общества, поскольку в наибольшей мере способны дестабилизировать деятельность государства.

Примечательно также и то, что общественная опасность соответствующих коррупционных преступлений во многом обусловлена сферой их совершения, значением соответствующей сферы для государства и общества, особенностями условий, в которых совершается преступление и которые во многом зависят от особенностей соответствующей сферы, особенности субъектов, вступающих в правоотношения в данной сфере и т. п. В частности, вполне очевидно, что для государства недопустимым является компрометация, которая исходит от лиц, совершающих коррупционные преступления. Такая компрометация тем больше, чем значимее соответствующий орган в системе государственного устройства. Следует учитывать и то, что отдельные органы государства выполняют деятельность, которая тесно связана с установлением справедливости, а потому совершение коррупционных преступлений сотрудниками этих органов наносит значительный вред самому пониманию и восприятию справедливости населением. Одним из таких государственных органов являются органы внутренних дел. Среди этих органов следует отметить органы ГИБДД, к которым у населения особенно пристальное внимание, что обусловлено характером функциональных обязанностей, которые государство возлагает на них ${ }^{7}$. Кроме того, органы ГИБДД всегда воспринимались и воспринимаются как органы государства, которые ближе всего к населению в силу особенностей той деятельности, осуществление которой возложено на них государством.

Степень общественной опасности соответствующего деяния отражается не только на процессе квалификации, но и на процессе расследования соответствующего преступления. Следователь должен как можно быстрее выявить факторы, негативно воздействующие на правопорядок и процесс деятельности соответствующего государственного органа. Это необходимо для предупреждения совершения новых преступлений и пресечения преступлений, которые продолжаются. Помимо этого, степень общественной опасности является показателем наличия определённых особенностей либо в обстановке совершения преступления, либо в способе и механизме, а также является характеристикой ценности соответствующего объекта уголовно-правовой защиты. Данные особенности имеют значение для выбора и определения системы мер и средств, которые могут быть использованы для обеспечения эффективности проводимого расследования конкретного преступления. Они значимы для формулирования соответствующей частной методики расследования и для выработки алгоритма расследования конкретного преступления.

Как показывает практика расследования коррупционных преступлений, на особенности их совершения влияют функциональные особенности деятельности соответствующего государственного органа, полномочия которого стремятся использовать соответствующие недобросовестные должностные лица этого органа ${ }^{8}$. В случае совершения коррупционных преступлений сотрудниками ГИБДД это использование властно-распорядительных функций данного органа внутренних дел, причём использование в собственных, корыстных интересах, вопреки интересам государства. Более того, такое использование компрометирует ГИБДД как орган государства, а потому страдает всё государство, поскольку подрывается вера населения в то, что государство способно восстанавливать справедливость и гарантировать её9. В связи с этим государству наносится серьёзный вред, выражающийся в дестабилизации соответствующей социальной ситуации. Поэтому незамедлительность в выявлении, оператив-

\footnotetext{
${ }^{7}$ Давыдов М.В. Проблемы борьбы с коррупцией в подразделениях ГИБДд // Наука и практика. 2015. № 2 (63). С. 41-44.

${ }^{8}$ Шкеля О.В., Раздобудина А.А. Некоторые проблемы, возникающие в области противодействия коррупции в подразделениях ГИБДД, и пути их решения // Общество и право. 2016. № 1 (55). С. 128-133.

${ }^{9}$ Малыхина Т.А., Каминский А.М. О некоторых вопросах, связанных с обжалованием сотрудниками органов внутренних дел решений о наложении дисциплинарных взысканий // Конвергенция в сфере научной деятельности: проблемы, возможности, перспективы: материалы Всерос. науч. конф. Ижевск: Изд. центр «Удмуртский университет», 2018. С. 245-249.
} 
ность в расследовании каждого конкретного случая совершения коррупции - это не только показатель эффективного установления истины и изобличение виновного, но это также поддержание стабильного правопорядка, режима законности, обеспечения справедливости.

Однако для того, чтобы оградить органы государства в лице ГИБДД от дискредитации, причиняемой совершением коррупционных преступлений, нужны эффективные действия органов расследования. Необходимо, чтобы совершение каждого действия сопровождалось решением стоящей тактической задачи, чтобы не было пустых, ненужных действий, которые не способны дать ничего, кроме суеты, создав массу сложностей. Деятельность по установлению истины должна быть основана на экономии средств и затрачиваемых усилий. Для этого необходима эффективная частная методика, которая бы основывалась на особенностях совершения рассматриваемого вида преступлений. Эта методика должна учитывать наиболее распространённые особенности совершения коррупционных преступлений в той или иной сфере. Это важно потому, что это позволит на основе разработанных рекомендаций быстро создать алгоритм деятельности, который сможет обеспечить успех при расследовании конкретного коррупционного преступления. От качества созданной частной методики будет зависеть качество расследования совершённого преступления.

Полномочия ГИБДД определены в Положении о государственной инспекции безопасности дорожного движения министерства внутренних дел Российской Федерации, утверждённом Указом Президента РФ от 15.06.1998 № 711 «О дополнительных мерах по обеспечению безопасности дорожного движения» ${ }^{10}$. Среди этих полномочий: осуществление государственного контроля (надзора) за соблюдением правил, стандартов, технических норм и различного рода нормативных требований, которые предъявляются в связи с обеспечением безопасности дорожного движения; регистрация автотранспортных средств; приём экзаменов на право управления автотранспортными средствами; выдача свидетельств на право перевозки опасных грузов; согласование маршрутов перевозки крупногабаритных грузов и ряд других полномочий. Как видно, названные полномочия носят властнораспорядительный характер, что проявляется в реализации полномочий по предоставлению тех или иных субъективных прав как физическим, так и юридическим лицам. Достаточно широкий круг полномочий, которые имеются у органов ГИБДД, в случае недобросовестности соответствующих должностных лиц может быть использован ими вопреки интересам службы, ради собственной корысти. Данные полномочия, по своей сути, при совершении коррупционных преступлений приобретают свойство орудий - инструмента для решения вполне определённой прикладной задачи, ориентированной на личный интерес. Посредством должностных полномочий злоумышленник приобретает возможность добиться преступного результата и остаться не выявленным. Следовательно, одной из важнейших особенностей, значимых для расследования, в коррупционных преступлениях является то, какие полномочия должностного лица использовались в ходе проводимого расследования.

Следует также отметить, что должностные полномочия могут выступать не только в качестве орудия преступления, но и в качестве стимула к его совершению. Это проявляется в том, что отдельные лица, не имеющие твёрдых нравственных устоев, могут соблазниться теми возможностями, которые предоставляет их должностное положение и использовать его для достижения противоправной цели. Как стимул должностные полномочия дают толчок для формирования благоприятных условий и среды для совершения коррупционных преступлений, тем самым сами становятся элементом этой среды. Кроме того, на их фоне формируются отношения между отдельными людьми, сотрудниками и должностными лицами, которые в свою очередь становятся благоприятным фоном для совершения соответствующего коррупционного преступления. Часто формируются даже определённые традиции, которые облегчают совершение соответствующих преступлений. Эти традиции часто преподносятся как средство для преодоления определённых бюрократических формальностей, но в качестве таких «формальностей» часто выступают действия, призванные оградить именно от бюрократического произвола. При этом используются полномочия, предоставленные законом соответствующему должностному лицу.

Всё это имеет место при совершении коррупционных преступлений в органах ГИБДД. Здесь, как было сказано выше, должностным лицам предоставляются значительные властно-распорядительные полномочия, использование которых способно принести значительный доход тем, кто ими злоупотребляет. Прежде всего, это связано с тем, что посредством реализации названных полномочий отдельным

\footnotetext{
10 Указ Президента РФ от 15 июня 1998 г. № 711 «О дополнительных мерах по обеспечению безопасности дорожного движения»// Собрание законодательства Российской Федерации 22 июня 1998 г. № 25. Ст. 2897.
} 
Методологические основы расследования коррупционных преступлений...

715

ЭКОНОМИКА И ПРАВО

2021. Т. 31, вып. 4

лицам могут предоставляться субъективные права, а при наличии определённых условий эти права могут либо существенно ограничиваться, либо их могут лишать. К сожалению, это вызывает у некоторых должностных лиц желание злоупотребить своими полномочиями ради личных интересов.

Одним из средств преодоления подобных злоупотреблений должностными полномочиями является ограничение возможности личного контакта между соответствующим должностным лицом и тем лицом, которое может получить или лишиться определённого субъективного права. Этого можно добиваться либо автоматизацией механизма предоставления или лишения этих прав, либо введением определённых промежуточных инстанций по получению соответствующих правоустанавливающих документов, когда лица, получающие эти документы, не обладают полномочиями по принятию соответствующих властных решений. В этом направлении ведётся организационная работа в органах ГИБДД и уже достаточно много сделано. Однако, и это вполне естественно, ещё остаётся много несделанного. Это часто связано с тем, что ещё далеко не всё можно сделать без непосредственного контакта между должностным лицом и лицом, в отношении которого должно быть принято соответствующее решение.

Но знание особенностей полномочий ГИБДД важно не только для того, чтобы иметь возможность своевременно упреждать совершение коррупционных преступлений. Оно также важно и для того, чтобы знать типичную картину совершения этих преступлений. На её основе должны формулироваться рекомендации, посредством которых можно оптимизировать расследование коррупционных преступлений, совершаемых сотрудниками ГИБДД. Должна быть использована закономерность о взаимосвязи между преступной деятельностью и деятельностью по её расследованию. Суть этой закономерности состоит в том, что эффективно лишь то расследование, которое максимально принимает во внимание особенности совершения конкретного преступления. Причиной является то, что расследование, по сути, всегда инициируется совершённым преступлением. Нет преступления - нет и его расследования. Особенности совершённого преступления обусловливают особенности его расследования.

Названная взаимосвязь и взаимозависимость имеет методологическое значение для расследования корыстных преступлений, совершённых сотрудниками ГИБДД. Здесь следует принимать во внимание на то, что названная взаимосвязь в наибольшей мере проявляется во взаимовлиянии способа, механизма совершения преступлений рассматриваемого вида и механизма проводимого расследования. В частности, на её основе формулируются рекомендации по преодолению противодействия проводимому расследованию ${ }^{11}$. Они основываются на знании того, что вполне определённые должностные полномочия, а также сформировавшиеся на их основе отношения с другими должностными лицами могут быть использованы вопреки интересам проводимого расследования ${ }^{12}$. В частности, они могут использоваться для дискредитации личности следователя, его профессиональных способностей и опыта, могут предприниматься действия, направленные на изъятие соответствующего уголовного дела из производства следователя, успешно ведущего деятельность по установлению истины ${ }^{13}$. В зависимости от особенности полномочий соответствующего сотрудника ГИБДД им могут предприниматься и иные действия, направленные на противодействие в установлении картины совершённого деяния. Эти особенности необходимо учитывать и заблаговременно принимать меры по нейтрализации такого противодействия. Знание об этом должно входить в основу соответствующей частной методики расследования.

Значение механизма совершения коррупционного преступления сотрудниками ГИБДД состоит также в том, что он позволяет определить не только общую картину совершённого преступления, но и установить источники, из которых можно получить уличающие виновного доказательства. При этом существует возможность выявить наиболее уязвимые места в системе защиты лица, стремящегося скрыть обстоятельства совершения соответствующего преступления. Следователь имеет возможность благодаря этому выстроить аргументацию виновности соответствующего должностного лица так, что она не только будет убедительной, но и сможет устоять перед контраргументами стороны защиты. То есть у следователя есть возможность не только полно и всесторонне исследовать обстоятельства совершённого преступления, но и создать систему доказательств, обосновывающих

\footnotetext{
${ }^{11}$ Варданян А.В. Противодействие предварительному расследованию: в продолжение научной дискуссии // Вестник Восточно-Сибирского института МВД России. 2021. № 1 (96). С. 137-145.

${ }^{12}$ Подольный Н.А. Предпосылки расследования преступлений // Российский следователь. 2014. № 8. С. 7-11.

${ }^{13}$ Подольный Н.А. Объективная истина или каким быть уголовному процессу России // Библиотека криминалиста. Научный журнал. 2012. № 4 (5). С. 224-237.
} 
правильность сделанных им выводов относительно виновности соответствующих сотрудников ГИБДД. Это важно не только для обеспечения реализации функции государственного обвинения в ходе уголовного судопроизводства, но и для того чтобы избежать возможности необоснованного привлечения к уголовной ответственности невиновного лица. Наличие необоснованных доказательствами тезисов обвинения влечёт за собой то, что эти тезисы не отображают истины по конкретному уголовному делу.

Изложенное является основанием для вывода о том, что коррупционные преступления, совершённые сотрудниками ГИБДД, имеют целый ряд особенностей, которые следует учитывать при расследовании. Их знание позволяет предпринять действия, оптимизирующие проводимое расследование. Данных особенностей достаточно много, что влечёт за собой утверждение о необходимости непросто адаптации уже существующих частных методик расследования коррупционных преступлений, а создания новой частной методики, которая бы содержала в себе рекомендации, учитывающие особенности названного вида коррупционных преступлений, что позволяло бы расследовать на высоком качественном уровне. При этом данная частная методика должна выстраиваться на определённом множестве типичных особенностей названных преступлений и принимать во внимание сложившуюся в практике специфику расследования

Поступила в редакцию 02.06.2021

Цыбульский Василий Васильевич, преподаватель кафедры уголовно-процессуального права и криминалистики Средне-Волжский институт (филиал) Всероссийского государственного университет юстиции (РПА Минюста России)» в г. Саранске 430003, Россия, г. Саранск, ул. Федосеенко, 6 E-mail: Vasilytsybulsky@yandex.ru

\section{V.V.Tsybulsky METHODOLOGICAL BASES OF INVESTIGATION OF CORRUPTION CRIMES COMMITTED BY TRAFFIC POLICE OFFICERS}

DOI: $10.35634 / 2412-9593-2021-31-4-711-716$

Corruption crimes committed by traffic police officers have features that distinguish them from other corruption crimes. These features are important for solving the issue of effective detection and investigation of crimes of this type. At the same time, special attention in the investigation should be paid to how traffic police officers use official powers granted to them by law, as well as to what subjective rights are granted as a result of their abuse of these powers. It is noteworthy that the official powers act in the course of committing corruption crimes by traffic police officers as a means of crime, as well as in some cases as an incentive to commit a specific crime of this type. In this regard, already at the initial stage of the investigation, the investigator must be ready to resist the perpetrators of the crime to establish all the circumstances of the crime. In accordance with these features, the private methodology for investigating corruption crimes committed by traffic police officers should include recommendations that take into account the specifics of the commission of these corruption crimes.

Keywords: corruption crimes, traffic police officers, methodological bases of investigation, private investigation methodology, official powers.

Tsybulsky V.V., Teacher of the Department of Criminal Procedure Law and Criminalistics Middle Volga Institute (branch) of the All-Russian State University of Justice (RPA of the Ministry of Justice of Russia) in Saransk Fedoseenko st., 6, Saransk, Russia, 430003

E-mail: Vasilytsybulsky@yandex.ru 